\title{
HUBUNGAN PERAWATAN TALI PUSAT DENGAN LAMA LEPAS TALI PUSAT PADA BAYI BARU LAHIR \\ DI PUSKEMAS LAKESSI \\ KOTA PAREPARE
}

\author{
Susianti \\ Susianti.asry@gmail.com
}

\begin{abstract}
ABSTRAK
Upaya mempercepat penurunan angka kematian ibu (AKI) dan AKB, Departemen Kesehatan telah melaksanakan berbagai program yang berhubungan dengan kesehatan ibu dan anak dan salah satunya pencegahan tetanus neonatorum. Upaya ini dilaksanakan dengan pencegahan infeksi pada persalinan dan perawatan bayi baru lahir termasuk perawatan tali pusat (Depkes RI,2007). Tujuannya Untuk mengetahui hubungan perawatan tali pusat dengan lama lepas tali pusat pada bayi baru lahir di Puskesmas Lakessi

Penelitian ini menggunakan metode observasional dengan menggunakan pendekatan analitik cross sectional, subyek penelitian adalah ibu postpartum yang memiliki bayi usia satu hari sampai lepasnya tali pusat, di Puskesmas Lakessi Kota Parepare. Teknik pengambilan sampel dengan teknik sample jenuh sejumlah 30 responden dengan alat ukur yang digunakan adalah checklist dan lembar observasi, analisis data menggunakan Kendall Tau.

Dari penelitian ini diperoleh 19 responden $(63,3 \%)$ melakukan perawatan tali pusat dengan baik, 8 responden $(26,7 \%)$ melakukan perawatan dengan kategori cukup dan 3 responden (10\%) melakukan perawatan tali pusat dengan kategori kurang, sedangkan untuk lama lepas tali pusat diperoleh 21 responden (70\%) dengan waktu lepas sedang, 5 responden $(16,7 \%)$ dalam kategori cepat, dan 4 responden $(13,3 \%)$ dalam kategori lama. Analisis uji Kendall Tau diperoleh hasil nilai signifikan 0,012 yang menunjukkan bahwa nilai $\mathrm{p}$ value $<0,05$. Ada hubungan yang signifikan antara perawatan tali pusat pada bayi baru lahir dengan lama lepas tali pusat. Bagi bidan diharapkan tidak hanya memberikan konseling saja tentang perawatan tali pusat tetapi sebaiknya didemonstrasikan bersama ibu.
\end{abstract}

Kata kunci : Perawatan tali pusat, bayi baru lahir, lama lepas.

Sumber : 19 buku, 3 jurnal, 


\title{
THE CORELATION OF CARE UMBILICAL CORD INNEWBORN WITHLONG OFF UMBILICAL CORD PUSKESMAS LAKESSI
}

\begin{abstract}
Accelerate efforts to reduce maternal mortality rate and infant mortality rate, the department of health has implemented various programs dealing with health mother and child and one of them tetanus neonatorum prevention .This effort implemented with the prevention of infection in childbirth and care of newborn infant including care umbilical cord ( indonesian ministry of finance , 2007 ) . The goal is to know the care relationships the umbilical cord with long off the umbilical cord at a new baby born in puskesmas lakessi

This research using methods observational using analytic cross sectional approach, subjects research is mother postpartum who has a bun of one days until off umbilical cord, at Puskesmas lakessi Kota Parepare. The sample techniques to technique sample saturated some 30 respondents with a measure used is checklist and sheets of observation, an analysis of data using kendall tau

From the study obtained 19 respondents ( 63,3\%) maintenance of the umbilical cord well , 8 respondents ( $26,7 \%$ ) maintenance category 3 respondents enough and ( $10 \%$ ) maintenance of the umbilical cord category less, the long off the umbilical cord obtained 21 respondents ( $70 \%$ ) with time off was , 5 respondents $(16,7 \%)$ in a category fast, and 4 respondents $(13,3 \%)$ in a category long. The analysis kendall know the results significant value 0,012 indicating that the $\mathrm{p}$ value $<0,05$.A significant relation exists between care the umbilical cord in newborn babies with long off the umbilical cord .For the is expected to not only give counseling just about care the umbilical cord but should demonstrated with mrs
\end{abstract}

Keywords : Umbilical cord care, newborn babies, longloose.

References : 19 books, 3 journals 


\section{LATAR BELAKANG}

Menurut World Health Organisation (WHO) tetanus dan penyakit infeksi merupakan penyebab utama kematian bayi. Tetanus neonatorum dan infeksi tali pusat menjadi penyebab kesakitan dan kematian secara terus menerus di berbagai Negara.

Setiap tahunnya 500.000 bayi meninggal karena tetanus neonatorum, dan 460.000 meninggal akibat infeksi bakteri. Angka kematian bayi (AKB) di Indonesia masih tergolong tinggi jika dibandingkan dengan negara-negara ASEAN seperti Singapura (3 per 1000 kh), Brunei Darussalam (8 per 1000 kh), Malaysia (10 per1000 kh), Vietnam (18 per $1000 \mathrm{kh}$ ), dan Thailand (20 per 1000 $\mathrm{kh})$.

Berdasarkan Survey Demografi Kesehatan Indonesia (SDKI) AKB di Indonesia tahun 2015 sebesar 23 per 1000 kelahiran hidup tetapi tercatat mengalami penurunan yaitu dari sebesar 35 per 1000 kelahiran hidup (SDKI 2002) menjadi sebesar 34 per 1000 kelahiran hidup (SDKI 2007). Menurut Depkes $75 \%$ kematian bayi terjadi pada masa perinatal (bayi usia 0-7 hari). Kematian neonatal kelompok umur 8-28 hari tertinggi karena infeksi sebesar $57,1 \%$ (termasuk tetanus, sepsis, pneumonia, diare), proporsi kematian karena tetanus neontorum 9,5\% (Depkes RI, 2008).

Tetanus ini dapat terjadi akibat perawatan atau tindakan yang tidak memenuhi syarat kebersihan, misalnya pemotongan tali pusat dengan menggunakan bambu atau gunting yang tidak steril, atau setelah tali pusat dipotong dibubuhi abu, tanah, minyak, daun - daunan dan sebagainya. Tali pusat mempunyai resiko besar untuk terkontaminasi oleh clostridium tetani pada 3 hari pertama kehidupan (Sodikin, 2009)

\section{METODE PENELITIAN}

Desain penelitian ini menggunakan metode observasional. Penelitian ini bertujuan untuk mengetahui korelasi antara perawatan tali pusat dengan lama lepas tali pusat. Metode pengambilan data berdasarkan pendekatan waktu yang 
digunakan adalah prospektif yaitu mengukur/mengumpulkan faktor resiko atau penyebab (variabel bebas) terlebih dahulu, kemudian mengikuti waktu tertentu baru mengukur akibat atau variabel terikat (Sulistyaningsih, 2010). Variabel bebas dalam penelitian ini adalah Perawatan Tali Pusat. Variabel terikat dalam penelitian ini adalah Lama Lepas Tali Pusat. Variabel pengganggu dalam penelitian ini adalah faktor-faktor yang mempengaruhi lama lepas tali pusat yaitu Timbulnya infeksi pada tali pusat, Kelembaban tali pusat, Kondisi sanitasi lingkungan sekitar neonatus. Populasi dalam penelitian ini adalah semua ibu post partum yang memiliki bayi hidup di Puskesmas Lakessi sebanyak 30 ibu post partum selama 6 minggu. Sampel penelitian ini adalah semua ibu post partum yang memiliki bayi hidup di lingkup Puskesmas Lakessi berjumlah 30 orang. Jadi Teknik pengambilan sampling menggunakan Sampel Jenuh. Alat yang digunakan dalam pengumpulan data adalah cheklist dan lembar observasi. Lembar observasi digunakan untuk mengukur lama lepas tali pusat. Observasi dilakukan dirumah klien. Analisis data dalam penelitian ini menggunakan analisis Non Parametrik yaitu Kendall tau.

\section{HASIL DAN PEMBAHASAN}

Tabel 1 Distribusi Frekuensi Responden di Puskesmas Lakessi Parepare Periode Mei-Juni 2016.

\begin{tabular}{llcc} 
Karakteristik & \multicolumn{1}{c}{ Parameter } & F & $\%$ \\
\hline Pendidikan & SD & 1 & 3,3 \\
& SMP-SMA & 27 & 90,0 \\
& PT & 2 & 6,7 \\
\hline \multirow{2}{*}{ Umur } & $<20$ & 7 & 23,3 \\
& $20-35$ & 19 & 63,3 \\
& $>35$ & 4 & 13,3 \\
\hline Paritas & Primipara & 12 & 40,0 \\
& Multipara & 18 & 60,0 \\
\hline Jk Bayi & Perempuan & 17 & 56,7 \\
& Laki-Laki & 13 & 43,3 \\
\hline Penjepit & Umbilical klem & 13 & 43,3 \\
Tali pusat & Karet & 17 & 56,7 \\
\hline Total & & 30 & 100
\end{tabular}

Sumber data: Data primer 


\section{Analisis Bivariat}

Tabel 2

Perawatan tali pusat dengan lama lepas tali pusat

di Puskesmas Lakessi Parepare

\begin{tabular}{|c|c|c|c|c|c|c|c|c|}
\hline \multirow[b]{2}{*}{ Lama lepas } & \multicolumn{2}{|c|}{ Baik } & \multicolumn{2}{|c|}{ Sedang } & \multicolumn{2}{|c|}{ Kurang } & \multicolumn{2}{|c|}{ Total } \\
\hline & $\mathrm{N}$ & $\%$ & $\mathrm{~N}$ & $\%$ & $\mathrm{~N}$ & $\%$ & $\mathrm{~N}$ & $\%$ \\
\hline Cepat & 4 & 13,3 & 1 & 3,3 & 0 & 0 & 5 & 16,7 \\
\hline Sedang (normal) & 15 & 50 & 5 & 16,7 & 1 & 3,3 & 21 & 70 \\
\hline Lama & 0 & 0 & 2 & 6,7 & 2 & 6,7 & 4 & 13,3 \\
\hline Total & 19 & 63,3 & & 6,7 & 31 & & 3010 & \\
\hline
\end{tabular}

Sumber: Data Primer

Tabel 3

Perawatan tali pusat dengan lama lepas tali pusat

di Puskesmas Lakessi Parepare

Periode Mei-Juni 2016.

Correlations

\begin{tabular}{lllrr}
\hline & & $\begin{array}{r}\text { Perawatan } \\
\text { Tali Pusat }\end{array}$ & \multicolumn{1}{c}{$\begin{array}{r}\text { Lama } \\
\text { Lepas }\end{array}$} \\
\hline $\begin{array}{l}\text { Kendall's } \\
\text { Tau_b }\end{array}$ & Perawatan Tali & Correlation & 1,000 &, $435\left(^{*}\right)$ \\
& Pusat & Coefficient & &, 012 \\
& Sig. (2-tailed) & 30 & 30 \\
& lamalepas & Correlation &, $435\left(^{*}\right)$ & 1,000 \\
& & Coefficient &, 012 &. \\
& Sig. (2-tailed) & 30 & 30 \\
\hline
\end{tabular}

* Correlation is significant at the 0.05 level (2-tailed). 


\section{PEMBAHASAN}

\section{Perawatan Tali Pusat Pada Bayi Baru Lahir}

Dari hasil penelitian pada tabel 2 dapat dilihat bahwa sebagian besar responden melakukan perawatan tali pusat pada bayi baru lahir dengan kategori baik hasil prosentase yang di dapatkan 63,3\% (19 responden), 8 responden $(26,7 \%)$ melakukan dengan hasil cukup dan 3 responden (10\%) melakukan perawatan tali pusat dengan kategori kurang. 2 dari tiga responden yang melakukan perawatan tali pusat dengan kategori kurang berumur $>35$ tahun dan berparitas multipara, responden merasa sudah banyak pengalaman sehingga tidak melakukan cuci tangan sebelum dan sesudah melakukan perawatan tali pusat, cara mengeringkan tali pusat juga hanya sekilas saja. Sedangkan 1 diantaranya berusia < 20 tahun, paritas primipara dan pendidikan SMP, responden belum ada pengalaman dalam merawat tali pusat dan kurangnya informasi yang diterima oleh ibu, baik melalui media cetak, media elektronik atau dari pengalaman orang lain, informasi yang diterima masih sangat terbatas. Sehingga ibu tidak melakukan perawatan dengan baik, sebagian besar cara perawatan tidak dilakukan seperti cuci tangan sebelum dan sesudah merawat tali pusat akan lebih langgeng daripada yang tidak didasari oleh pengetahuan (Notoatmodjo) karena menurut ibu itu tidak penting, cara mengeringkan tali pusat dilakukan sekedarnya saja, dan saat tali pusat terkena BAK hanya di keringkan saja tidak dicuci dengan air bersih. Pengetahuan atau kognitif merupakan domain yang sangat penting untuk terbentuknya tindakan seseorang, karena dari pengalaman dan penelitian ternyata sikap dan perilaku yang didasari pengetahuan.

Dari hasil penelitian pada tabel 1 didapatsebanyak 18 responden (60\%) dengan paritas multipara, dari 18 responden 13 responden $(43,3 \%)$ melakukan perawatan tali pusat dengan baik. Disini dapat digambarkan bahwa responden yang merupakan ibu hamil multipara yang paling banyak melakukan perawatan tali pusat dengan baik. Paritas dapat mempengaruhi responden dalam melakukan perawatan tali pusat, dimana seseorang yang sudah pernah mengalami perawatan bayi sebelumnya dapat dijadikan pengalaman untuk perawatan bayi berikutnya.

Berdasarkan tabel 2 hasil penelitian perawatan tali pusat pada umur responden sebagian besar responden berumur 20-35 tahun melakukan perawatan tali pusat dengan baik sebanyak 14 reponden dengan prosentase (46,67\%), Umur ini merupakan umur muda dimana organ-organ tubuh manusia masih berfungsi dengan baik. Misalnya, informasi ditangkap dengan mata dan telinga yang masih berfungsi dengan baik, dan mengaplikasikan dengan baik. Hal ini sesuai dengan Notoatmodjo (2003) yang menyatakan umur ibu 
mempengaruhi bagaimana mengambil keputusan dalam pemeliharaan kesehatannya. Berdasarkan hasil penelitian pada tabel 1 menunjukkan bahwa responden terbanyak pada kelompok tingkat pendidikan SMP-SMA dengan melakukan perawatan tali pusat dengan baik 17 responden dengan prosentase $56,67 \%$, disini dapat digambarkan bahwa responden yang merupakan ibu post partum dengan tingkat pendidikan menengah, paling banyak melakukan perawatan tali pusat dengan baik. Tingkat pendidikan seseorang dapat berpengaruh terhadap pengambilan suatu sikap karena dengan pengetahuan yang cukup dapat mengambil suatu keputusan yang rasional. Hal ini didukung oleh teori yang dikemukakan oleh Notoatmodjo (2003), yaitu penentuan sikap yang utuh dipengaruhi oleh tingkat pendidikan dan pendidikan kesehatan satusatunya faktor yang mempengaruhi perilaku seseorang, tetapi dipengaruhi oleh faktor pendukung eksternal yang secara langsung dapat mempengaruhi perubahan prilaku, seperti sarana yang dimiliki, fasilitas lain yang diberikan oleh orang lain untuk terjadi perubahan perilaku.

\section{Lama lepas tali pusat}

Dari hasil penelitian pada tabel 2 dapat dilihat bahwa sebagian besar responden mengalami lama lepas tali pusat dalam waktu normal dengan prosentase $70 \%$ (21 responden), 5 responden (16,7\%) mengalami cepat lepas dan 4 responden $(13,3 \%)$ mengalami lama lepas dengan waktu lebih dari 7 hari, luka yang kering akan lebih cepat sembuh dari pada basah, ada beberapa faktor yang mempengaruhi lama lepas tali pusat yaitu timbulnya infeksi pada tali pusat, cara perawatan tali pusat, kelembaban tali pusat dan kondisi sanitasi lingkungan dan ada beberapa faktor pendukung pengeringan dan pelepasan tali pusat bayi yaitu kebersihan daerah tali pusat, nutrisi ASI, kepatuhan ibu dalam merawat tali pusat. Dan dampak pada psikologis ibu, membuat ibu menjadi cemas, khawatir dan takut dengan kesehatan bayinya.

Dari hasil penelitian pada tabel 3 didapat sebanyak 21 responden dengan prosentase $(70 \%)$ Dari hasil penelitian tentang lama lepas tali pusat pada bayi baru lahir dengan batas sedang/normal, 8 responden $(26,67 \%)$ jenis kelamin perempuan dan 13 responden $(43,3 \%)$ berjenis kelamin laki-laki. Sebagian besar penduduk Indonesia adalah perempuan, Dari hasil penelitian pada tabel 1 didapat sebanyak 13 responden dengan prosentase $(43,3 \%)$ menggunakan pengikat umbilical klem, 17 responden $(56,67 \%)$ menggunakan karet. Disini di dapatkan hasil lama pelepasan tali pusat yang menggunakan karet paling rendah 5 hari dan paling tinggi 8 hari dengan rata-rata 5,17 sedangkan yang menggunakan umbilical klem paling rendah 5 hari dan paling tinggi 9 hari dengan rata-rata 6,15 jadi dapat disimpulkan lama lepas yang paling cepat yaitu menggunakan Karet. 


\section{Hubungan Perawatan tali pusatpada bayi baru lahir Dengan lama lepas tali pusat.}

Dari tabel 2 dapat diketahui bahwa sebagian yaitu 15 responden yang melakukan perawatan dengan baik $(50,00 \%)$ dan 15 responden yang melakukan perawatan dengan baik mengalami lama lepas tali pusat secara normal (50\%). Dua responden mengalami lama lepas tali pusat dengan kategori waktu lama kemungkinan karena tidak melakukan perawatan tali pusat kurang baik $(0,6 \%)$.

Berdasarkan hasil analisa data uji statistic dengan menggunakan KendallTau menunjukkan nilai taraf signifikan 0,012 <0,05 (p-value<0,05) maka Ho ditolak, artinya ada hubungan yang bermakna antara perawatan tali pusat pada bayi baru lahir dengan lama lepas tali pusat. Faktor yang mempengaruhi lama lepas tali pusat yaitu timbulnya infeksi pada tali pusat, cara perawatan tali pusat, kelembapan tali pusat dan kondisi sanitasi lingkungan dan ada beberapa faktor pendukung pengeringan dan pelepasan tali pusat bayi yaitu kebersihan daerah tali pusat, nutrisi ASI, kepatuhan ibu dalam merawat tali pusat.

\section{KESIMPULAN DAN SARAN}

Ada hubungan yang signifikan antara perawatan tali pusat dengan lama lepas tali pusat dengan nilai $\mathrm{p}=0,012$. Berdasarkan kesimpulan di atas, maka ada beberapa upaya yang perlu diperhatikan. Bagi Responden diharapkan ibu tidak hanya mendapatkan informasi saja tentang perawatan tali pusat, tetapi mendapat pembelajaran tentang perawatan tali pusat yang benar. 


\section{DAFTAR PUSTAKA}

Al-Qur'an dan Terjemahannya (Ayat Pojok Bergaris) Departemen Agama RI, Semarang: CV. Asy Syifa'

Anantasari,K.M.R. 2010. Perbedaan Penyembuhan Pusat pada Bayi Baru Lahir Antara yang di Rawat Alkohol 70\% dan Tanpa Alkohol di Wilayah Kerja Puskesmas Purwosari Kabupaten Pasuruan. Skripsi. Universitas Negeri Solo

Buckley, I. 2009. From Zero to Succes (kata-kata nasehat motivator dahsyat). Citra Medika. yogyakarta.

Departemen Kesehatan RI. 2002. Hubungan karakteristik Ibu Hamil dengan Kejadian Anemi. htpp://oneskripsi.com (diakses tanggal 26-6-2012) . 2007. kesehatan Ibu dan Anak. www. Kesehatan

Ibu dan Anak.co.id, diakses 20 Januari 2014

Dinas Profinsi. 2008. Profil Kesehatan Yogyakarta DIY.Dinas Kesehatan Profinsi DIY. Hal 2

Hidayat A. 2009. Asuhan neonatus, Bayi dan balita Buku PratikumMahasiswa Kebidanan. EGC.Jakarta

Jacob, T. 2004. Etika Penelitian Ilmiah. Yogyakarta, Warta Penelitian Universitas Gajah Mada (Edisi Khusus)

Manuaba I.2009. Ilmu Kebidanan Penyakit Kandungan danKeluarga Berencana untuk Pendidikan Bidan. ECG. Jakarta

Meilani, N dkk. 2009. Kebidanan Komunitas.Fitramaya. Yogyakarta Notoatmodjo S.2005.Metode Penelitian Kesehatan. Rineka Cipta. Jakarta .2007. Promosi Kesehatan dan Ilmu Perilaku. Rineka Cipta. Jakarta . 2003. Pengantar pendidikan kesehatan dan Ilmu perilaku Kesehatan,

Yogyakarta . 2003. Ilmu Kesehatan Masyarakat. Rineka Cipta. Jakarta. Permanasari, D.K. 2009.Perbedaan Lama Pelepasan Tali Pusat antara Perawatan Tertutup dengan Yang dibiarkan Terbuka.Tesis.Universitas Muhammadiyah Yogyakarta. Yogyakarta 
Putri, T.A. 2011, Gambaran Pengetahuan Ibu Nifas Tentang Perawatan Tali Pusat pada Bayi Baru Lahir di BPS Vitarina Pekalongan Lampung Timur.Journal kebidanan.Vol 4, no 7. Lampung

Prawiroharjo S. 2000. Buku Acuan Nasional PelayananKesehatanMaternal dan Neonatal. Tridasa printer. Jakarta . 2009. Ilmu Kebidanan edisi V. Tridasa printer. Jakarta Poerwandari, K. 2005. Pendekatan Kualitatif Untuk Penelitian Perilaku Manusia. Jakarta. Fakultas Psikologi Universitas Indonesia.

Rahmawati, E. S. 2005. Observasi Perawatan Tali Pusat Terhadap Waktu Pengeringan dan Pelepasan Tali Pusat di Ruang C RSUP.Dr .Soeradji Tirtonegoro Klaten.Journal Ilmu Kesehatan. Volume 2, no 4 Yogyakarta

Saifudin. B. A. 2002. Acuan Nasional Pelayanan Kesehatan Maternal dan Neonatal. Jakarta. Yayasan Bina Pustaka.

Salmah.2006. Asuhan Kebidanan Antenatal .EGC. Jakarta

Sulistyaningsih, 2010, Buku Ajar Dan Panduan Praktikum Metodologi Penelitian Kebidanan, Stikes Aisyiyah, Yogyakarta.

Sulistyaningrum.R dan dkk. 2013. Perbedaan Fiksasi Tali Pusat dengan Benang dan Klem Plastik Tali Pusat Terhadap Lama Pelepasan Tali Pusat Bayi di BPS Dyah Widya Susilawati. Journal Bidan Prada.Vol.2, no 1 Jawa Tengah.

Utami. 2010. Perbedaan Lama Lepas Tali Pusat Perawatan dengan Menggunakan Kasa Steril dibandingkan dengan Menggunakan Kasa Alkohol. Skripsi.UNS 